\title{
Co-Creation in Practice III: Co-Creating Age-Friendly Routes (Zaragoza)
}

\section{Summary of Co-Creation Project ${ }^{1}$}

\section{Problem Focus}

Physical accessibility, as well as sensory access, are important elements to configure the improvement of the friendliness of urban environments, for all citizens, but especially for older adults. The possibility of moving and enjoying the city in a safe and accessible way represents another way to promote equality, ultimately avoiding the inequalities that the environment can generate for older citizens. In Zaragoza, different participatory processes aiming at the improvement of older citizens lives have been conducted by the city administration. In these processes, older people have expressed their demand for safe and well-equipped spaces for strolling and moving around and that encourage physical activity.

\section{Value Proposition}

The service provides all relevant information on the facilities that need to be improved or added to support the mobility and social connection of older adults in a district and improve access to all types of services. This is a new service that did not exist before as it combines the possibility of creating age-friendly routes to walk calmly and safely through the city with the possibility of making demands to improve those routes according to the needs of older adults. As an online service, it is more relevant and comprehensive, optimises usability for older adults and is easily accessible and continuously updated.

\footnotetext{
${ }^{1}$ This introduction is derived from the case study of our Interactive co-creation guide: https://cocreation.mobile-age.eu/guidebook/case-studies/zaragoza1

This chapter is based on the Mobile Age project deliverable D3.4 Senior Citizen Engagement Report Zaragoza: https://mobile-age.eu/images/pdf/deliverables/WP3/D3.4.pdf
} 


\section{Limitations of Existing Services}

There exist already quite a number of printed information about resources for older citizens in all districts of the city. They deal with different kinds of objects and provide information in different degrees of details. Most of them have been compiled and designed for senior adults but not with them. Many older adults complained about the shortcomings of some areas with regard to the equipment they felt they needed to have. The ICT unit of Zaragoza's public administration was informed by service providers such as Senior Citizen Meeting Centers that it was a very arduous job for older people to report incidents as there was no clear way to identify where the problem was, how to report it to the municipality and, finally, how to get it resolved.

\section{Co-Created Service}

The result is a service better than the existing ones in several respects. First, it provides comprehensive and relevant information supporting the planning of activities (accessibility of buildings and routes, information about toilets and benches). Second, it is a user-friendly and accessible technical design for older adults which provides relevant and up-to-date information facilitating social participation of older people in the city of Zaragoza. Information may be searched via a map that is optimised for older people and via listings. All information is provided by a responsive application, which can be accessed from desktop PCs, tablets and Smartphones, with particular emphasis on accessibility. In addition, the service is based on open data (up to date, accessible via API, machine readable) and co-created data, relevant to the citizens' needs. As the service is linked to open data the respective data providers are responsible for updates and the service provider is relieved from this job.

\section{Reason for Inclusion in this Book}

The third co-creation project described in this book was managed by the city council of Zaragoza ${ }^{2}$, one of the project partners of the Mobile Age project. In the project, two departments were involved: the Department of Elderly Care and the Technical Office of participation, transparency and open government. The work presented here was conducted between May and December 2017. What is interesting in the case of the co-creation project in Zaragoza in comparison to the ones presented from Bremen is that the governance structure and stakeholders were different. Whereas in Bremen, the co-creation projects were coordinated and managed by a research institute in cooperation with the local district councils and service providers, in Zaragoza it was the public administration itself that coordinated and managed the co-creation project. At the same time, all projects focused on agefriendly cities and communities; the services developed were in all cases map-based digital services. Hence, for the purpose of this book, this is an interesting case for comparison, as it illustrates how differences in governance structures impact on a co-creation project, for example with respect to its scope, engagement of stakeholders and sustainability of the outcome.

\footnotetext{
${ }^{2}$ www.zaragoza.es
} 
Although, I have not personally conducted the co-creation activities in Zaragoza, I was involved their planning, revision and evaluation. I have been to Zaragoza three times between July 2016 and November 2017. In November 2017, I was able to participate in one of the co-creation events - a walking session with older adults. In addition, I met with the Spanish colleagues for workshops during our project meetings three times (in Bremen, Thessaloniki and Brussels). Furthermore, we had biweekly video calls between all partners where we discussed our progress, shared insights and also materials and resources. The chapter is based on the report that colleagues from Zaragoza city council prepared for reporting to the European Commission.

\section{Introduction to Field Site}

The co-creation activities in Zaragoza took place at the same time as the ones in Bremen Hemelingen and after the first co-creation project in Bremen Osterholz. This means that the project was informed by the lessons learned from Bremen Osterholz. The co-creation project was carried out in three districts of Zaragoza in three phases. The districts were chosen upon recommendation of the Department of Elderly Care based on previous good working relations. In addition, in all districts there existed groups of older people engaged in walking clubs and familiar with using GPS. The three districts have a different socio-economic structure.

\section{District 1: Zaragoza Centro (May '17-June '17)}

Central district has 53.411 inhabitants of which $27.27 \%$ are over 65 years old. It corresponds to a municipal district of high economic level (average net income $17,846.86 €)$. Its geographic location corresponds to the downtown area of the city, with numerous urban commercial spaces. There is one Senior Citizen Centre in the district.

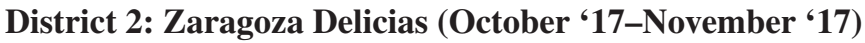

District of Delicias is the district with the highest population density, with several old housing areas and a total population of 106,371 inhabitants, of which $23.05 \%$ are over 65 years old. It has a low to average level of income (average net income 10,282.8€) and has three Senior Citizens Centres.

\section{District 3: Zaragoza Almozara (November '17-December '17)}

District of Almozara is located near the Historic Quarter of the City. It is a small neighbourhood with a population of 29,229 inhabitants and $18.65 \%$ of people are above 65 years. The district has an average income level (average net income $11,717.25 €)$, and it is one of the neighbourhoods which experienced most social and urban transformation in the last decades. 


\section{Co-Creation Process}

The co-creation projects in all three districts were similar and comprised of eight sessions. The following Fig. 1 provides an overview of the process.
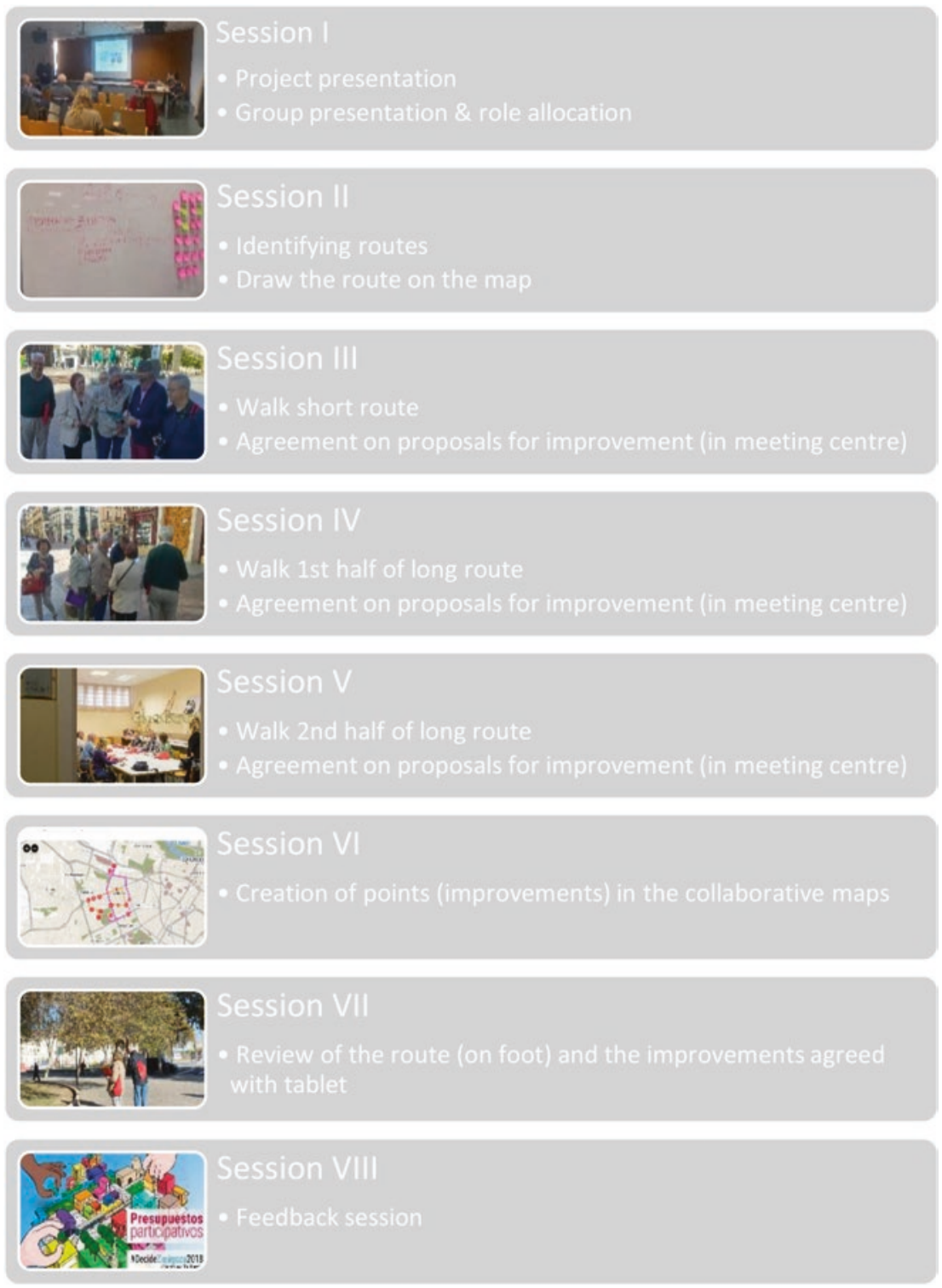

Fig. 1 Overview process for co-creation projects on age-friendly routes 


\section{Governing and Managing Co-Creation}

There exist already quite a number of printed information about resources for Third Agers in the districts. They include different kinds of objects and provide information in different degrees of details. Most of them have been compiled and designed for senior adults but not with them.

- When the co-creation process in Zaragoza began, the directors of the Senior Citizen Centres informed the co-creation team in Zaragoza that in some centres, older residents organise themselves to take walks in different neighbourhoods in the city and on the outskirts. Many of them complained about the shortcomings of some areas with regard to the equipment they felt they needed to have. They argued that it was a very arduous job for older people to report incidents as there was no clear way to identify where the problem was, how to report it to the municipality and, finally, how to get it resolved.

- The official website www.zaragoza.es contains information on many services that can help citizens to communicate complaints and suggestions to the city council and to create shared routes with all citizens through a map. These are two independent services that were not directly featured on the city council's senior citizens' website.

The co-creation project as conducted in Zaragoza made the following value proposition: The service to be developed provides all relevant information on the facilities that need to be improved or added to support the mobility and social connection of older adults in the district and improve access to all types of services. This was a new service that did not exist before as it combines the possibility of creating age-friendly routes to walk with the possibility of filing requests to improve them according to the requirements of the people who use them. As an online service, it is more relevant and comprehensive, exploits the potential of digital media technology, optimises usability for older adults, is easily accessible and continuously updated.

\section{Engaging Stakeholders}

In Zaragoza, the co-creation process was managed by the city council. In each district, a core-group of six to eight older adults participated. For example, the cocreators in Zaragoza Central District consisted of four males and two females aged 65-80. They were comparably well educated, physically (one had a leg mobility impairment) and psychologically healthy; all lived independently. None lived in an institutional setting. Overall, the participants were familiar with digital technologies. Only one participant had never used a computer. Almost half of the participants engaged actively in political and volunteering work in the district. 
The co-creators in each of the three co-creation projects included older adults living in the respective district and with some bond to the district. They needed to be still mobile, although at least one had to have some kind of limitation in his/her movements (wheelchair or any kind of problem walking). For the project team, it was important to include a similar number of women and men. In each group there had to be somebody experienced in digital photography and another person familiar with digital technologies.

\section{Co-Creating a Service Concept}

In order to familiarise participants with the ideas and objectives of the co-creation projects in each of the three districts, staff from both participating city council departments introduced the project's ideas and objectives.

To start the co-creation project participants needed to familiarise themselves with the project, so the first session was dedicated to understanding the main contents. To do so, the experts from each of the City Council Departments explained both, the Mobile Age project and the idea of age-friendly routes. Participants then had the opportunity to ask questions about the process, methods and expected results.

\section{Frequent Destinations (Data Collection)}

Once the project's objectives, procedures and timeline were explained, the way of collecting information about the most frequently visited destinations was discussed. It was agreed that the participating Senior Citizens Centre in each of the three districts, should be the starting point for each of the age-friendly routes as they are centrally located and an important point of reference for older residents in any of the three districts.

In order to determine the route and destination, each of the groups completed a data sheet about their district. For this exercise, a card was designed: "FREQUENT DESTINATIONS". Each participant was asked to consult with six further people about frequent/important destinations in the district. In the subsequent session, each participant returned with a completed form (Fig. 2).

Iniatially, it appeared as if participants had no problem in understanding the task. However, at the next session the project team discovered that some (two out of six), had misunderstood the objectives of the task in that they were specifically looking for problematic routes (e.g. sidewalks in bad conditions) rather than frequently used ones. A further round of data collection was initiated and a set of destinations collected. In a subsequent workshop, two destinations had to be selected as there was not enough time to work on more than two routes per district.

\section{Affinity Diagrams}

In order to select two destinations out of the set of different destinations collected by the participants, the project team in Zaragoza used an affinity diagram. Since there was only limited time, it was agreed to select a long and a short route. For 
example, in the first district, the Pilar Square was the most popular route. Since this was a long route (distance from Senior Citizen Centre), the second route had to be a short route. Here the second popular route, a route to the Medical Centre, which passes by El Corte Inglés (Shopping Centre) was chosen.

\section{Working with Open Data}

\section{Collaborative Maps}

The next objective was to agree on the actual route (most adequate, convenient, nice and/or fast) and mark the route on the collaborative maps. This was done collaboratively and visualised on a digital screen. To do so the project team used the City Council Website's collaborative map service as a tool for decision making, sharing experiences and configuring the way through which the participants observe their district (new collaborative cartographies available to everyone).

In addition, the facilities published by the City Council as open data appeared on the map on which the routes were marked, which was very useful to detect those

Fig. 2 Frequent destinations

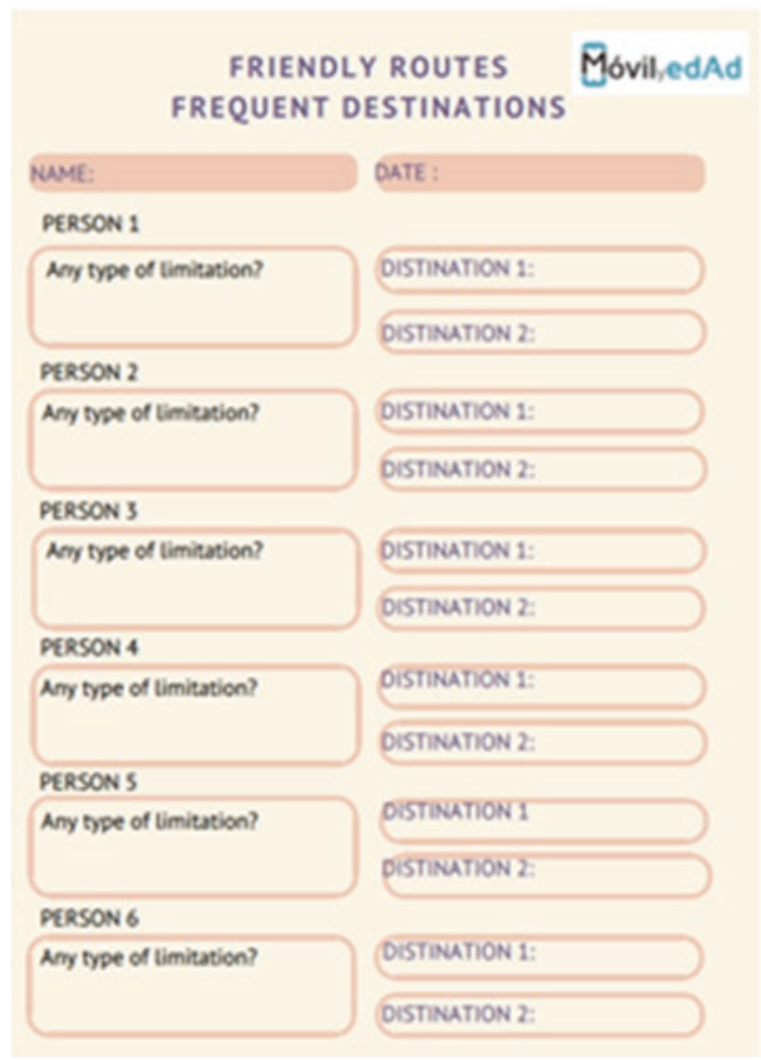


elements that the participants considered necessary to have listed in the map. The facilities published by the City Council as open data appeared on the map on which the routes were marked. This was very useful for determining those elements that the participants considered relevant elements of the map (Fig. 3).

All data were visualised on the same digital map. This provided the opportunity to both: decide on the exact route that would be taken to the final destinations and give participants the opportunity to learn about this interactive tool and familiarise themselves with the digital services of the City Council (Fig. 4).

Once destinations were agreed and the routes were marked in the collaborative maps, the participants had to agree which aspects/elements of a route were important to be analysed while walking this route. The following criteria were proposed by the city council:

- Benches

- Traffic signal timing

- Curb recesses

- Bus stops (access difficulties)

- Interesting points (public bathrooms).

After discussing these criteria, the participants agreed to retain them and did not add any further elements. In order to consider them, a template/form was developed that participants could complete while walking the designated routes. For each element, participants had to list the kind of improvement requirement and the exact geo-location (coordinates).

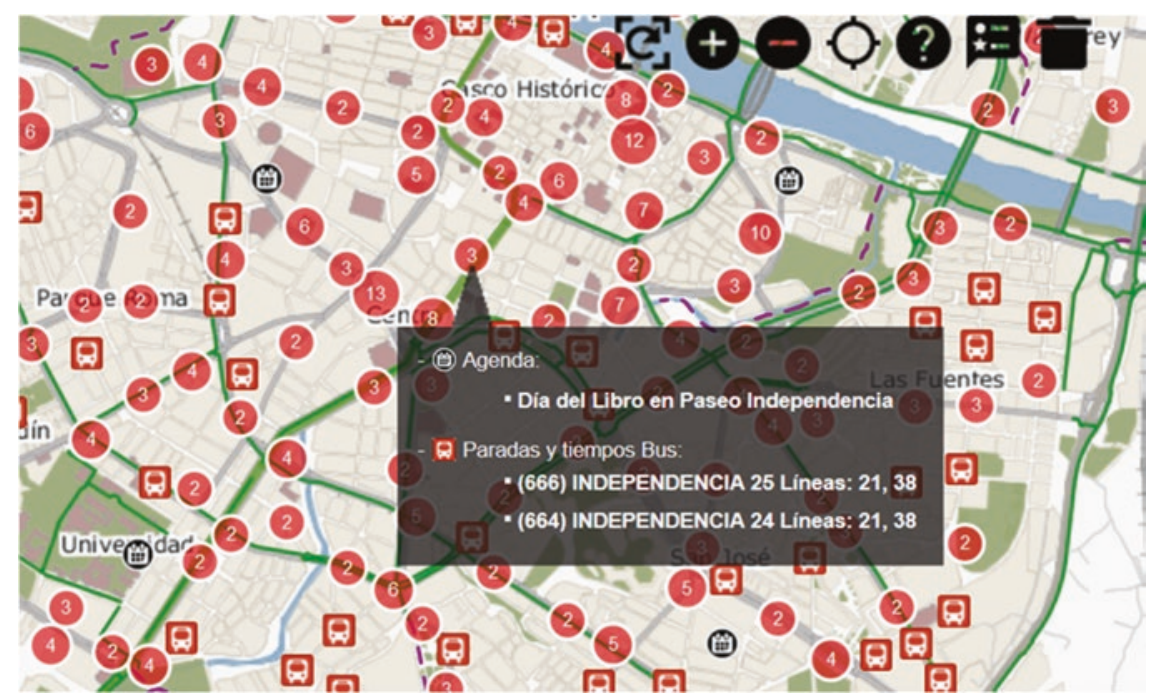

Fig. 3 Screenshot of collaborative maps service 
This form was evaluated and improved after the first walks. After the first round of walks, the pre-selected criteria were slightly adapted and categorised in primary and secondary elements:

Primary elements:

- State of sidewalks (Tiles, slides, paving, recesses...)

- Benches

- Traffic lights and crosswalks

- Points of interest (public bathrooms, green spaces, fountains, bins, dirt, mailboxes, etc.).

Secondary elements:

- Bus/tram stops (access, information panel, etc.

Before the walks, each of the older participants was assigned a task. They were either responsible for taking photographs, for documenting the GPS coordinates or walked in pairs of two to observe, analyse and document ideas for improvement. For both routes, the starting point was the Senior Citizen Centre. The long route, was carried out in two sessions (the first, from the beginning to the midpoint of the route and the second the remaining section). During the walks, the group observed the different elements to evaluate in order to improve the route. The walk was carried out as a group, although the observation and documentation was individual.

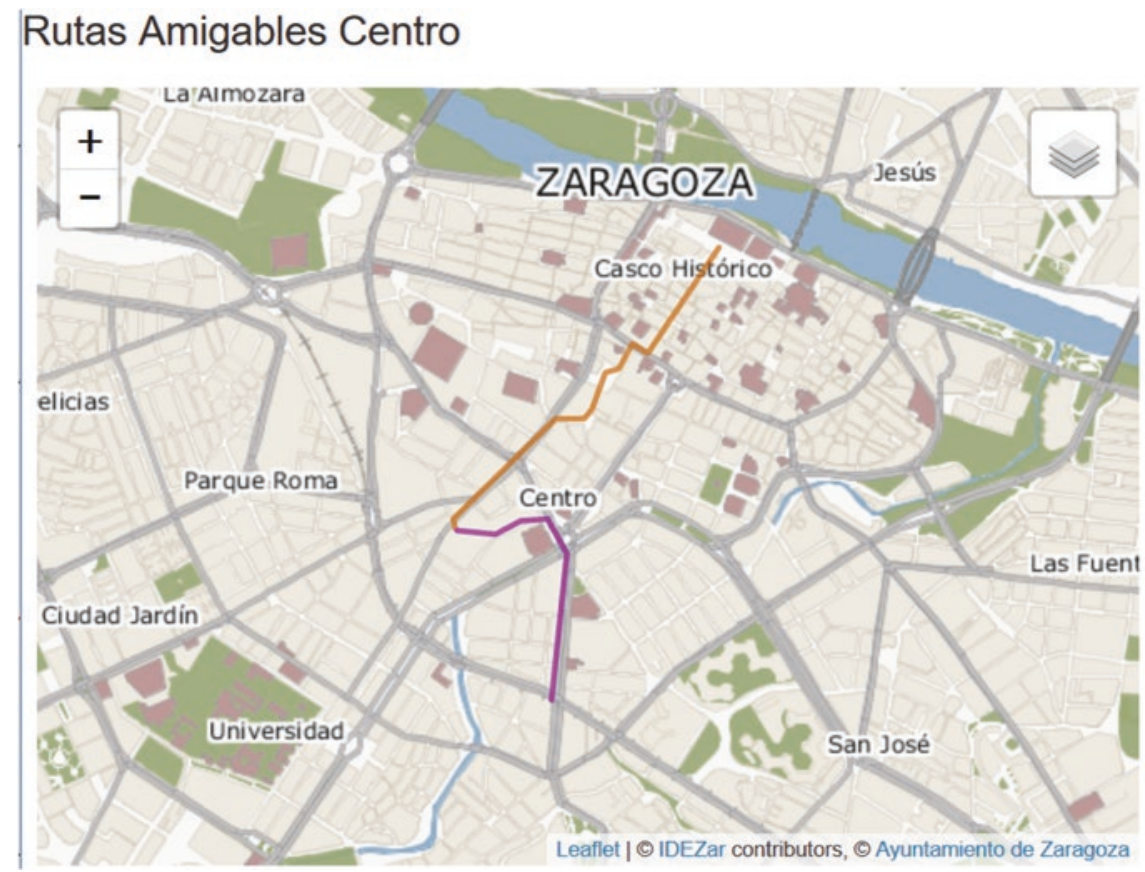

Fig. 4 Routes 1 and 2 as depicted in the collaborative map for centro district 
Whenever a member of the group detected a possible improvement proposal, the group discussed it, and in cases where it was confirmed as an interesting proposal for improvement, a photograph and location references were taken.

When reaching the midpoint of the route (in the case of the long route), the route was reversed in the opposite direction, so that the team had the opportunity to review the proposals made and even incorporate new ones. When returning to the Senior Citizen Centre, the photographs were projected with the objective of deciding if the proposal was going to be maintained or not. For this purpose, the information obtained and the suggestion for improvement as well as its motivation were analysed. If, on this basis, a suggestion was selected, the requested improvement was described as comprehensively as possible.

The following session, started at the midpoint of the long route and followed the same methodology. This process was appropriate and, apart from the time constraints, did not pose any problems. The process allowed every participant to actively participate and put suggestions forward, it also allowed the whole group to come to a shared consensus (e.g. based on the shared experience of walking the route together).

The last session in any district, was dedicated to the complete itinerary of the two routes in order to validate the information that appears in the collaborative maps. The participants checked if the markers that appear in the collaborative maps corresponded with the proposals they made. All the information was displayed on tablets, while the group walked the route and this way could be evaluated on site. This task was described as rewarding and satisfying by the participants, as they saw that their proposals had been introduced on the City Council website-one step closer towards the realisation of an improvements.

In order to correctly locate each improvement an excel sheet was designed to gather all the information. Below are two screenshots of the collaborative maps developed. Every mark represents a required action (Fig. 5).

\section{Summary of Co-Creation Process and Output}

For the work carried out in Zaragoza, the first co-creation project in Bremen provided a starting point, as both cases were interested in map-based services. Whereas this was a new way of engaging (older) citizens in the creation of services, Zaragoza was already very advanced in the technical provision of open government data (e.g. the city council has been working on their APIs for more than a decade now). The co-creation project in Zaragoza hence, was not reliant on the technical infrastructure provided by the Mobile Age project but used their own infrastructure to ensure the sustainable provision and maintenance of the service. The service was also continuously promoted on the city council's Website.

The results of the co-creation project, informed on the one hand repair activities of the city council in order to maintain the physical infrastructure; they also informed investment decisions for improving the physical infrastructure (e.g. the installation 

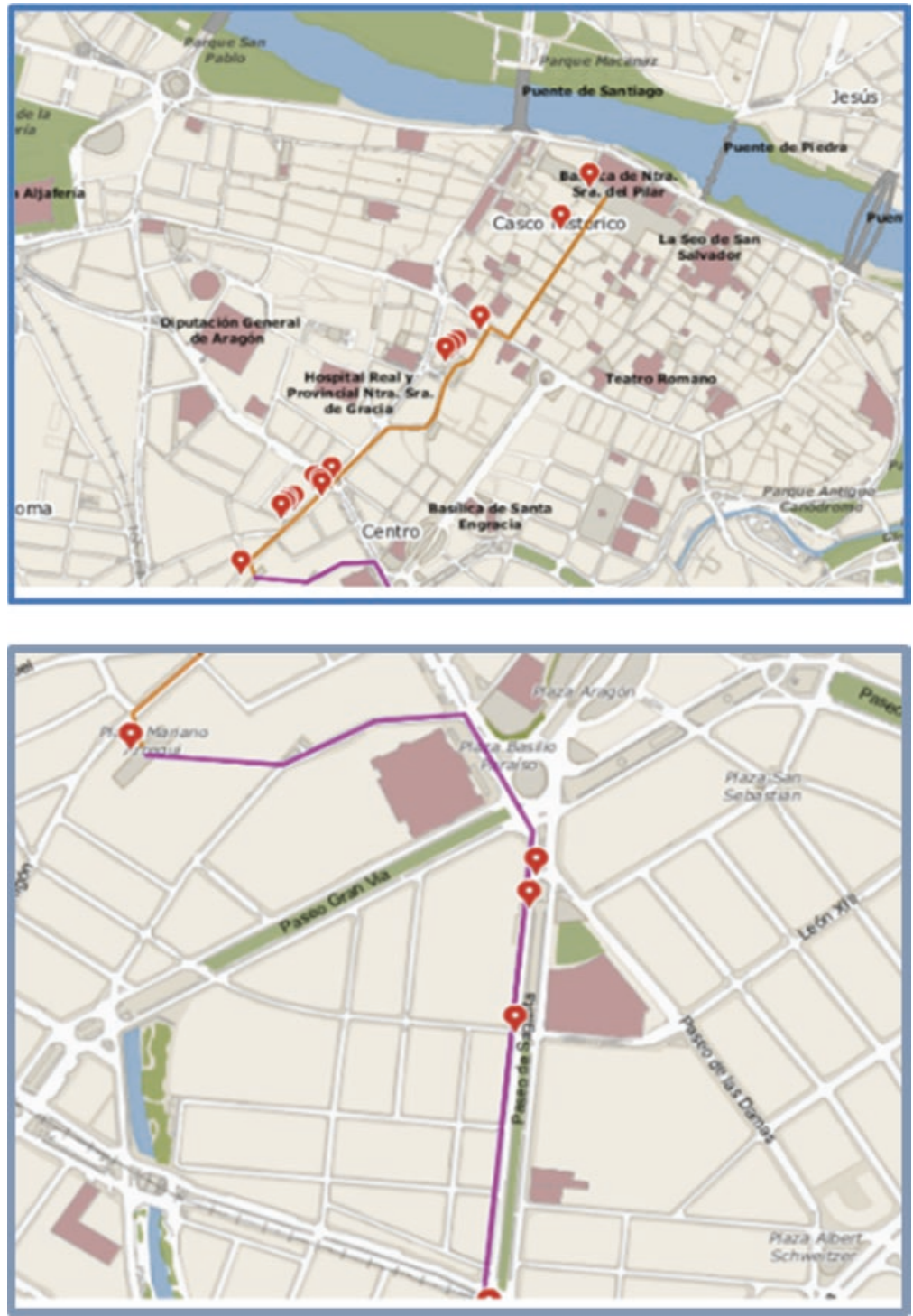

Fig. 5 Final collaborative maps (https://www.zaragoza.es/sede/servicio/mapa-colaborativo/579)

of new benches). Part of the recommendations developed by the co-creation project were pitched for the annual participatory budgeting process in which the city pledges to finance civic suggestions. It was hence relayed back to citizens who could take the final decision on which improvements should receive funding.

The canvas below provides a summary of the final service outcome (Fig. 6). 


\begin{tabular}{|c|c|c|c|c|}
\hline \multirow{2}{*}{$\begin{array}{l}\text { Key partners } \\
\\
\text { ICT Department } \\
\text { Department of } \\
\text { Elderly Care } \\
\text { Department for } \\
\text { Urban } \\
\text { Development \& } \\
\text { Infrastructure }\end{array}$} & $\begin{array}{ll}\text { Key activities } \\
\text { - } \\
\text { Review } \\
\text { information } \\
\text { - } & \text { Act on citizen } \\
\text { reports }\end{array}$ & \multirow{2}{*}{$\begin{array}{c}\text { Value } \\
\text { proposition } \\
\text { provide all relevant } \\
\text { information on the } \\
\text { facilities that need to } \\
\text { be improved and } \\
\text { ways for } \\
\text { communicating } \\
\text { suggestions for } \\
\text { improvement }\end{array}$} & $\begin{array}{l}\text { Relationship } \\
\text { ageing-in-place }\end{array}$ & \multirow{2}{*}{$\begin{array}{c}\text { Target audience } \\
\text { (Older) citizens from } \\
\text { Zaragoza }\end{array}$} \\
\hline & $\begin{array}{l}\text { Key resources } \\
\text { Collaborative } \\
\text { maps \& open data } \\
\text { infrastructure; } \\
\text { Existing inter- } \\
\text { governmental } \\
\text { collaborations }\end{array}$ & & $\begin{array}{c}\text { Channels } \\
\text { Online collaborative } \\
\text { map service }\end{array}$ & \\
\hline \multicolumn{2}{|c|}{ Cost structure } & \multicolumn{3}{|c|}{ Revenue Stream } \\
\hline \multicolumn{2}{|c|}{ Part of service portfolio } & \multicolumn{3}{|c|}{ not applicable } \\
\hline
\end{tabular}

Fig. 6 Final canvas for co-created service in Zaragoza

Open Access This chapter is licensed under the terms of the Creative Commons Attribution 4.0 International License (http://creativecommons.org/licenses/by/4.0/), which permits use, sharing, adaptation, distribution and reproduction in any medium or format, as long as you give appropriate credit to the original author(s) and the source, provide a link to the Creative Commons license and indicate if changes were made.

The images or other third party material in this chapter are included in the chapter's Creative Commons license, unless indicated otherwise in a credit line to the material. If material is not included in the chapter's Creative Commons license and your intended use is not permitted by statutory regulation or exceeds the permitted use, you will need to obtain permission directly from the copyright holder.

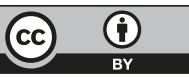

